(2) Open Access Full Text Article

REVIEW

\title{
A perspective on the benefit-risk assessment for new and emerging pharmaceuticals in Japan
}

This article was published in the following Dove Press journal:

Drug Design, Development and Therapy

31 March 2015

Number of times this article has been viewed

\section{Tetsuya Tanimoto}

Division of Social Communication System for Advanced Clinical

Research, Institute of Medical Science, University of Tokyo, Tokyo, Japan
Correspondence: Tetsuya Tanimoto Division of Social Communication System for Advanced Clinical Research, Institute of Medical Science, University of Tokyo, 4-6-I Shirokanedai, Minato-ku, I08-007I, Tokyo, Japan

Tel +8I 364092068

Fax $+8 \mid 364092069$

Email tetanimot@yahoo.co.jp
Abstract: The universal health care system in Japan is facing a historical turning point as a result of the increasing fiscal burden, rapidly aging society, and a decreasing population. To understand the challenges and opportunities in the Japanese pharmaceutical market, which occupies one tenth of the global share, this review highlights several issues related to the benefitrisk assessment that is unique to the modern Japanese society: 1) regulatory system for new drug development; 2) health hazards related to pharmaceuticals ("Yakugai" in Japanese); 3) drug lag; 4) problems and controversies in the vaccination policy; and 5) clinical study misconduct. The regulatory process places a significant importance on Japanese data collection regardless of data accumulation from other countries. Because Yakugai has repeatedly caused tragedies and social disputes historically, the regulatory judgments generally tend to be more prudential when safety concerns are raised for new and emerging pharmaceuticals. Such a regulatory system has caused more than several years of approval delays compared to delays in other countries. The problem of drug lag still lingers on despite several regulatory system revisions, while the solution is incompatible with the elimination of Yakugai because the lag potentially reduces the risk of unpredictable adverse events. The Japanese vaccination policy has also received a lot of criticism, and needs improvements so that the decision-making process can be more transparent and scientifically based. Additionally, repeated clinical study misconduct damaged the reputation of Japanese clinical studies with unnecessary defrayment in health insurance; therefore, the medical community must change its inappropriate relationship with the industry. The problems surrounding pharmaceuticals are related to centralized, strict drug pricing control under the universal health coverage. Although the current government attempts to facilitate innovative research and development of novel therapeutics in Japan, further reforms should be explored for patients who need new and emerging pharmaceuticals.

Keywords: MHLW, PMDA, Yakugai, drug lag, vaccination policy, clinical study misconduct

\section{Introduction}

Japan established the universal health care system in 1961, and the population achieved relatively sophisticated and egalitarian health care at low medical expenditures. ${ }^{1,2}$ However, Japan is facing a historical turning point with an increasing fiscal burden as well as a rapidly aging and decreasing population; the population in 2013 was approximately 127 million, and the productive age population (15-64 years old) was $62.1 \%$, whereas the child population ( $0-14$ years old) was a mere $12.9 \%$, and the aged population ( 65 years old or older) was as high as $25.1 \% .^{3}$ Toward the coming decades, Japan needs to address the unprecedented demographic change: the population in 2050 is estimated to decrease to 97 million with a $38.8 \%$ aged population. Reflecting the steadily growing number of the elderly population, the total national health expenditures increased to JPY 39.2 trillion (8.3\% of the gross domestic product) in the fiscal year (FY) $2012 .{ }^{4}$ 
The expenditures for pharmaceuticals were JPY 9.3 trillion in FY 2011, and the Japanese pharmaceutical market occupied $11.7 \%$ in the global market. ${ }^{5}$ The expenditures reached JPY 10.2 trillion in FY 2013. Japan has a similar drug regulatory system as in the United States, Europe, and other developed countries. The central government office responsible for drug regulation is the Ministry of Health, Labor, and Welfare (MHLW). ${ }^{6}$ In collaboration with the MHLW, the regulation is conducted by the Pharmaceuticals and Medical Devices Agency (PMDA). ${ }^{7}$ However, a benefit-risk assessment in the Japanese pharmaceutical regulation is not always based on the same rational reasoning that exists in Western countries, even though regulatory science receives a lot of attention. ${ }^{8,9}$

This review will present a perspective concerning the background for new drug development in Japan in five topic areas: 1) regulatory system for new drug development; 2) health hazards related to pharmaceuticals ("Yakugai" in Japanese); 3) drug lag; 4) problems and controversies in the vaccination policy; and 5) clinical study misconduct. These selected topics will help readers obtain insights regarding the benefit-risk assessment for new and emerging pharmaceuticals with both a historical and a cultural context that is unique to Japan.

\section{Regulatory system for new drug development in Japan}

In the US, the Food and Drug Administration (FDA), which is an agency within the US Department of Health and Human Services, is responsible for new drug development, vaccines, medical devices, and other biological products. ${ }^{10}$ In Europe, the European Medicines Agency (EMA) plays a similar role as a decentralized agency of the European Union. ${ }^{11}$ In Japan, the MHLW and the PMDA handle the regulatory affairs concerning new pharmaceuticals and devices. ${ }^{6,7}$

The MHLW is the final regulatory authority in the central government. Approvals of new drugs are authorized by the Minister of Health, Labor, and Welfare under the Pharmaceutical Affairs Law (renamed the Pharmaceuticals and Medical Devices Affairs Law in November 2014). In 1961, the Japanese government introduced the universal health care system. ${ }^{1,2}$ Within this system, pricing of medical costs including all approved drugs is strictly controlled. As a general rule, it is prohibited to simultaneously charge inside and outside the public insurance (so-called mixed medical treatment). This means once a doctor uses an unapproved drug, none of the treatment services can be covered under the public insurance. This seemingly irrational system was upheld in a decision made by the Supreme Court in 2011.
Thus, the MHLW possesses a strong power for drug regulation throughout Japan by using strict price control.

On the other hand, the PMDA is an independent administrative agency that performs scientific reviews for the marketing authorization of new drugs, vaccines, and devices. The agency is responsible from the beginning of preliminary nonclinical phases through the late phases including pivotal clinical trials. The PMDA gives advice for drug developments, reviews all scientific data submitted from pharmaceutical companies, publishes review reports for drug approvals, and gives instructions for authorized prescribed information. After the market approvals, the agency continues to monitor safety reports and issue safety alerts when problems emerge. In addition, the PDMA provides relief compensation for sufferers from adverse drug reactions and contaminated biological products. ${ }^{12}$ Thus, the PMDA focuses on three areas of interest: 1) pharmaceuticals and medical devices review; 2) post-marketing safety; and 3) adverse health effects relief service.

The review method itself seems to be similar among the FDA, the EMA, and the PMDA concerning a benefitrisk assessment of new and emerging treatments. All these authorities review nonclinical data as well as clinical trials under the international regulatory harmonization. However, the PMDA could have a different interpretation even on similar data submitted to the FDA and the EMA, and each regulatory authority sometimes may reach different conclusions. ${ }^{13-15}$ Generally, the PMDA requires the submission of data for Japanese subjects even if a drug has already been approved and used in other countries. That is, the regulatory review places a significant importance on Japanese data collection regardless of data accumulation in other countries. As shown in Figure 1, new drugs usually gain their first approval in other countries such as the US and the EU. Responsible pharmaceutical companies may already have approval regarding the drugs' safety and effectiveness through pivotal randomized clinical trials in non-Japanese patients. However, if the clinical trials do not include Japanese patients, the PMDA requires conducting new clinical trials in Japan. After the completion of such domestic trials, the company can submit a new drug application, which usually causes a delayed approval in Japan, notoriously known as the "drug lag." 16,17

The reason for the use of Japanese subjects is to confirm ethnic differences concerning pharmacokinetics, effectiveness, safety problems, and medical backgrounds. It is true that some drugs may have different profiles among patients with different ethnic backgrounds. ${ }^{18,19}$ Concerns about this 


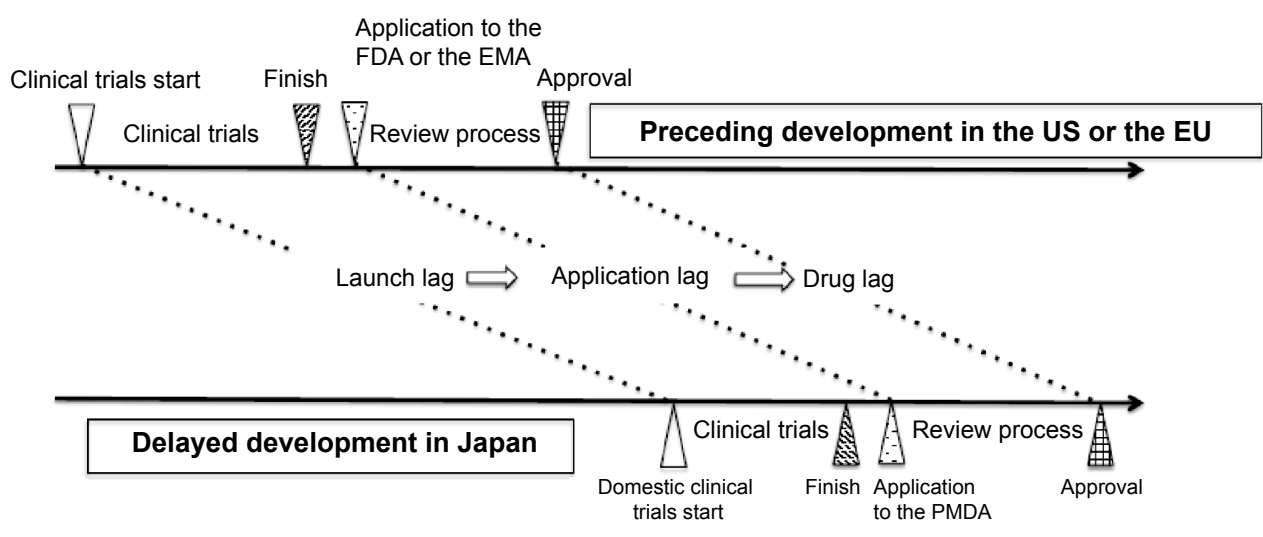

Figure I Typical drug development pattern in Japan.

Notes: A new drug is typically approved in the United States or the European Union ahead of Japan by several years, a situation called the "drug lag." The delays of clinical trials create launch lags, and the application delays to the regulatory authority create application lags. These delays result in Japanese approval delays. Although the time for regulatory review is improving, the drug lag still remains a problem because of delays in other processes.

Abbreviations: FDA, US Food and Drug Administration; EMA, European Medicines Agency; PMDA, Pharmaceuticals and Medical Devices Agency.

approach include: the number of patients from Japan is usually only a few tenths of patients from abroad in a data package submitted for regulatory approval. Such a small Japanese sample size in clinical trials can rarely detect major differences between Japan and other countries before market entry. In addition, patients are usually enrolled into trials just because they live in Japan. Rarely considered are the facts of whether patients have unique genetic backgrounds or other influences such as past, family, and social histories. The requirements for collecting Japanese patients' data might be a customary regulation rather than scientific reasoning. More discussions are needed regarding the propriety to collect and analyze small Japanese samples. Should the "customary" regulation outweigh the need to provide a treatment opportunity with as few delays as possible, especially for patients with life-threatening diseases?

Another unique point is that the review processes in the PMDA generally pose a higher importance on safety issues compared to other countries. In the past, many health hazards related to pharmaceuticals have caused social problems in Japanese society as shown in Table 1, and the regulatory authority has been seriously criticized. As a result, the regulatory judgments tend to be more prudential, especially, when safety concerns are raised for new drug applications. For example, erythropoietin is approved for the treatment of anemia for cancer patients in other countries. However, it is not yet approved in Japan because there are concerns about increased incidence of death or tumor progression. ${ }^{20,21}$

All countries have their own jurisdiction over their unique health care system that exists within their cultural and historical context, even in the global interconnected 21 st century. The characteristic features of the Japanese regulatory system can be summarized in two points: the health hazards related to pharmaceuticals and the drug lag. The details of these two points will be discussed in the following section.

Table I Major health hazards related to pharmaceuticals and administrative reforms in Japan

\begin{tabular}{ll}
\hline Year & Events \\
\hline 1962 & $\begin{array}{l}\text { Withdrawal of thalidomide, which caused around } \\
\text { I,000 birth defects } \\
\text { Withdrawal of clioquinol, which caused around } \\
\text { I0,000 patients to develop SMON }\end{array}$ \\
$1970 \quad \begin{array}{l}\text { Establishment of the fund for relief for patients suffering } \\
\text { from adverse drug reactions }\end{array}$ \\
$1983 \quad \begin{array}{l}\text { Tainted blood products caused HIV infection in nearly } \\
\text { 2,000 hemophiliac patients }\end{array}$ \\
1987 & $\begin{array}{l}\text { Reorganization in the fund for adverse drug reaction relief } \\
\text { and R\&D promotion }\end{array}$ \\
1987 & $\begin{array}{l}\text { Tainted blood products caused HCV infection in more than } \\
\text { I0,000 patients }\end{array}$ \\
1993 & $\begin{array}{l}\text { Suspension of MMR vaccine program, which caused nearly } \\
\text { 2,000 aseptic meningitis sufferers }\end{array}$ \\
1994 & $\begin{array}{l}\text { Withdrawal of sorivudine, because of interaction with 5-FU, } \\
\text { which caused the death of I8 patients }\end{array}$ \\
1994 & $\begin{array}{l}\text { Reorganization of the Organization for Pharmaceutical Safety } \\
\text { and Research }\end{array}$ \\
1997 & $\begin{array}{l}\text { Establishment of Pharmaceuticals and Medical Devices } \\
\text { Evaluation Center } \\
\text { Interstitial pneumonia associated with gefitinib resulted in a } \\
\text { class-action lawsuit }\end{array}$ \\
2002 & $\begin{array}{l}\text { Establishment of the PMDA } \\
\text { Suspension of HPV vaccination after the controversy about } \\
\text { CRPS being associated with vaccination }\end{array}$ \\
&
\end{tabular}

Abbreviations: SMON, subacute myelo-optico-neuropathy; HIV, human immunodeficiency virus; R\&D, research and development; HCV, hepatitis C virus; MMR, measles-mumps-rubella; 5-FU, 5-fluorouracil; PMDA, Pharmaceuticals and Medical Devices Agency; HPV, human papillomavirus; CRPS, complex regional pain syndrome. 


\section{Health hazards related to pharmaceuticals}

In the Japanese society, the health hazards related to pharmaceuticals (Yakugai) have repeatedly caused tragedies and social disputes..$^{22}$ Given the above, there have been major and minor revisions and reforms regarding pharmaceutical regulations in the last 5 decades. Table 1 chronologically summarizes major events. After having experienced major health hazards and class-action lawsuits, the government has reiterated revisions of the Pharmaceutical Affairs Law and updated the reporting system of adverse drug reactions, as well as reforms for related organizations. They also reformed pharmaceutical regulatory systems, introduced modernized drug review and approval methods, and instituted a drug safety monitoring system. Furthermore, in 1980, the government started the relief system for adverse drug reactions. This system provides financial relief for patients suffering from health hazards related to pharmaceuticals. These operations have been performed in the PMDA since 2004 in collaboration with the MHLW.

Historically, multiple birth defects caused by thalidomide would symbolize serious tragedies brought by health hazards related to pharmaceuticals. ${ }^{23}$ The drug was introduced in Japan as a sedative in 1958 without a meticulous regulatory review. In 1961, it was withdrawn in the former West German Republic. It was almost an additional 10 months later when the drug was withdrawn in Japan. While in use, it was estimated there were approximately 1,000 birth defects; however, the government officially acknowledged only 309 patients. In the late 1950s, a neurological disease called subacute myelo-optico-neuropathy (SMON) became prevalent throughout Japan. Reports indicate that over 10,000 patients were diagnosed with SMON up until 1970. ${ }^{24}$ Doctors and the public initially believed the cause to be a viral infection. However, clioquinol, used for intestinal problems, was identified as the true cause of SMON, and the drug was finally withdrawn from the market.

During the early 1980s, tainted blood products from the US caused an infection in Japanese hemophiliacs. They contracted human immunodeficiency virus (HIV). ${ }^{25,26}$ Nearly 2,000 out of around 5,000 patients were infected with iatrogenic HIV until heated products for virus inactivation became available in 1985. The delay of heated products was severely criticized, and led to criminal lawsuits. Similarly, more than 10,000 people were assumed to have had hepatitis $C$ virus (HCV) infection through tainted blood products. Although the most responsible product fibrinogen was withdrawn in the United States in 1977, the unheated product was sold in
Japan until 1987..$^{27,28}$ These tragedies greatly contributed to the reforms of regulatory and safety monitoring systems, and to the establishment of the PMDA.

In 1989, the Japanese government introduced the measlesmumps-rubella (MMR) vaccine into the routine vaccination program. After nearly 2,000 patients suffered from aseptic meningitis, the policy was abandoned in $1993 .{ }^{29}$ Initially, the incidence of aseptic meningitis was estimated to be one in several hundred thousands. However, when reported, actual cases were one in several thousands. This event might have increased disbelief against vaccination among the general public, and a prudential attitude about vaccine recommendation in the MHLW. In April 2013, the human papillomavirus (HPV) was introduced into routine vaccination programs. However, just after that, there were a number of cases of an adverse reaction similar to complex regional pain syndrome (CRPS) among young girls. ${ }^{30-32}$ Although the causal relationship is still controversial, the government has suspended the recommendation of the vaccination since June 2013.

In 2002, an epidermal growth factor gefitinib (Iressa ${ }^{\circledR}$; AstraZeneca, London, UK) was approved for non-small-cell lung cancer. Japan was the first country in which the new molecularly targeted drug gained approval before going global. This drug possesses a novel anticancer mechanism unlike traditional cytotoxic drugs, and the mass media called it a kind of magic bullet. As a result of its apparent lower adverse reactions, it became popular quickly. However, a severe adverse reaction including interstitial pneumonia led to a class-action lawsuit. ${ }^{33,34}$ In 2013, the Supreme Court acquitted the company and the government, but this lawsuit resulted in a conservative attitude toward the benefit-risk assessment for new and emerging treatments among the regulatory authority.

Thus, repeated health hazards related to pharmaceuticals have made the Japanese government cautious toward approving new and emerging treatments. In addition, the mass media tend to have extreme coverage for health hazards related to pharmaceuticals. Therefore, to avoid criticisms and lawsuits, the regulatory authority supposedly demands a higher level of safety standard compared to other countries. The higher safety standards would be one of the reasons for the drug lag, that is, most drugs take longer to reach the Japanese market. However, the delay is not always a bad thing. For example, rofecoxib (Vioxx ${ }^{\circledR}$; Merck, Whitehouse Station, New Jersey, USA), a selective cyclooxygenase-2 inhibitor, was approved in 1999 for use in the US. It was estimated to have caused tens of thousands of heart attacks prior to being banned in $2004 .{ }^{35}$ Because of the drug lag, Japan did not approve the 
drug at that time and avoided the health hazards. This event supports a report that suggested a longer launch lag of clinical trials in Japan was associated with fewer safety-related regulatory actions after market approval. ${ }^{36}$

\section{Drug lag}

For more than a decade, the pharmaceutical regulations have received serious criticism over the approval delays in Japan compared to other countries. ${ }^{2,16,17}$ The drug lag problem has become a major concern not only among pharmaceutical companies and medical professionals, but also among the general public, and has attracted significant attention from the mass media.

For example, in March 2007, a monoclonal antibody eculizumab (Soliris ${ }^{\circledR}$; Alexion Pharmaceuticals, Cheshire, Connecticut, USA) used for a rare disease was approved in the US. ${ }^{37}$ At the time of the Japanese regulatory review for approval in October 2009, the drug had already been approved in 33 countries. Although several phase III studies had been conducted in other countries, ${ }^{38-40}$ Japanese regulation required submission of domestic phase II studies, and the launch delay of clinical trials led to a drug lag. The Japanese approval was in April 2010, with a three-year delay compared to the approval of the drug in the US. ${ }^{41}$ This is a typical course of a drug lag as shown in Figure 1. Clinical trial delays create launch lags, and application delays to the regulatory authority create application lags. These delays result in Japanese approval delays, which are referred to as a drug lag.

In a previous comprehensive report, ${ }^{17}$ the researchers analyzed 398 new drugs approved in the US, the EU, and Japan between 1999 and 2007. The difference between approval times based on when drug approval was granted in the US was 2.7 months for the EU and 41.0 months for Japan, revealing a striking drug lag in Japan. There are also several disease-specific analyses concerning this issue. There were 23 standard psychiatric drugs approved in the US and in the UK between 2000 and 2011. On the contrary, there were only 13 psychiatric drugs approved during the same time period in Japan. ${ }^{42}$ In addition, for the 13 approved drugs, the drug lag in Japan averaged 51 months behind the UK and 87 months behind the US. The drug lag affected other fields as well. Of the 36 standard neurological drugs approved in the US, the researchers revealed a median approval delay of 87 months for only 21 neurological drugs introduced to Japan from 1999 to $2010 . .^{43}$ For 30 oncology drugs, the researchers found a median drug lag of 29.9 months behind the US and 21.3 months behind the EU from 2000 to $2009 .{ }^{44}$
An investigation of drugs for hematological malignancies between January 2000 and March 2014 found a median of 42.0 months approval delay among 16 drugs approved both in Japan and in the US, and there was no apparent trend of a reduced drug lag during the study period. ${ }^{45}$

Several previous reports identified the causative factors related to the drug lag. A report analyzed the time lags in Japan, the US and the EU, and found that the time lag related to the submission of applications was longer for in-licensed products and for non-Japanese companies. ${ }^{16}$ The authors suggest that to market a drug in Japan, a multinational company would likely choose development strategies with higher success probability, rather than focus on direct costs and expected sales. In the subsequent report, the authors also suggest that the drug lag had advantageous effects on drug development success, and that explains the persistent delays in the development and launch of new drugs in Japan. ${ }^{46}$ Another recent study between April 2009 and March 2012 points out that drug approvals are delayed when the application packages cannot use data from foreign clinical trials and when they involve pivotal trials of open-label, one-armed design. ${ }^{47}$

After growing public criticisms against the drug lag, the MHLW and the PMDA have implemented several countermeasures to reduce the lag. These measures include encouragement to join global clinical trials (GCTs) for pharmaceutical companies, increasing staffing at the PMDA to reduce review times, and maintaining the drug price at a premium to pay for new drug development. In recent years, more GCTs are including Japanese patients especially in pivotal trials. ${ }^{48}$ The PMDA and the MHLW advocate that the inclusion of GCTs for Japanese drug approval would reduce the drug lag. As for the staffing of the PMDA, published materials report that there was a threefold increase in 2013 from the less than 200 staff numbers of the review and safety section in $2004 .{ }^{49}$ According to an analysis, the median review period was reduced from 18.3 months in 2004 to 10.1 months by $2013 .{ }^{50}$ Thus, the reduced review period would have partly contributed to the reduction of the drug lag. ${ }^{51}$ However, the problem of the drug lag itself still lingers on with an amount of several years because of the launch lag and the submission lag on the whole. ${ }^{52}$

Some researchers indicate that the essential cause of a drug lag is the disadvantage of uniform drug pricing under the universal health coverage. ${ }^{53}$ That is, there is not enough financial incentive for pharmaceutical companies to develop new drugs earlier for the Japanese market. In contrast, the US pharmaceutical companies can set their 
own drug prices. In Japan, the MHLW and the Central Social Insurance Medical Council determine drug pricing based on the price of similar drugs sold in Japan, cost for manufacturing, and prices in other developed countries. ${ }^{54}$ Once the price is set, every 2 years thereafter, the government performs a price reduction, and better-sold drugs in the Japanese market tend to receive more of a price reduction (Figure 2). ${ }^{55}$ As a result, the government sets the price of new drugs at a lower level than that in the US or other countries. ${ }^{56-58}$ On the other hand, the market share of off-patent branded drugs is larger than that of generic drugs, even though the former is generally more expensive than the latter and the government tries to increase the use of generic drugs. ${ }^{59}$ If the Japanese hope to reduce the drug lag, the government needs to reform such an uniformly controlled pricing system, and allow the Japanese pharmaceutical market to become more competitive. The MHLW has started providing an exemption since April 2010, allowing a pharmaceutical company to maintain the on-patent branded drug price at a premium when the company conducts new drug development requested by the government. The influence on the drug lag of this policy remains to be seen.

\section{Problems and controversies in the vaccination policy}

The MHLW has also received a lot of criticism regarding the drug lag concerning vaccines, and the lack of scientific and rational approach for their vaccination policy compared to other developed countries. ${ }^{2,30,60-65}$ After World War II, the MHLW policy was to use only domestically manufactured vaccines in Japan, to protect domestic vaccine manufacturers from international competitors, serving as a kind of non-tariff

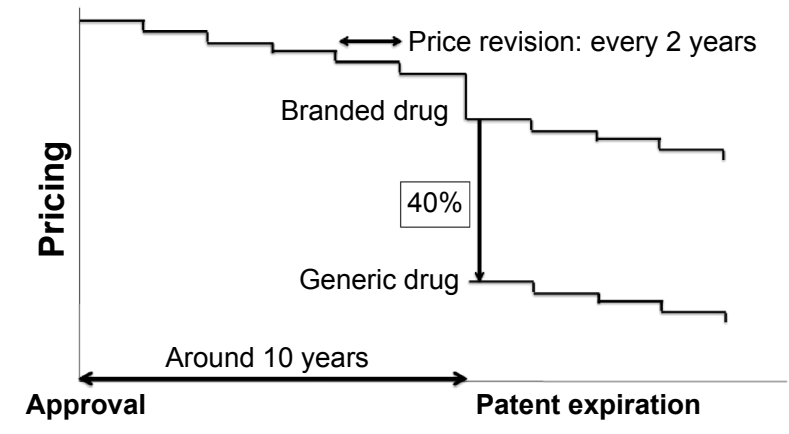

Figure 2 Drug pricing system in Japan.

Notes: Pricing of drugs is strictly controlled by the central government under the universal health coverage. After market approval, the price of a drug is reduced every 2 years. When a patent expires in approximately 10 years, generic drugs will appear with a price reduction of around $40 \%$ compared to the price of the off-patent branded drug. When the pharmaceutical company conducts new drug development requested by the government, the on-patent branded drug will be made available at a premium to maintain the price in line with the newly introduced policy in 2010 . entry barrier. However, the policy brought a significant vaccine lag in the 21 st century. Reported in a 2012 study, 20 common vaccines were approved in the UK, and only four vaccines were approved in Japan. ${ }^{66}$

The most striking case involves an inactivated polio vaccine (IPV), which had a vaccine lag of 30 years. 2,60,61 While Japan had eliminated wild poliovirus in 1981, the government continued to use domestically manufactured, live-attenuated oral polio vaccine until September 2012, instead of using IPV. As a result, more than 80 cases of vaccine-associated paralytic poliomyelitis occurred during that period. Some pediatricians and a local government had begun to import IPV by themselves. Because of growing public criticism, the MHLW reluctantly approved an IPV based on a limited domestic clinical trial in April 2012. The vaccine has been approved in France and globally since 1982. Domestic vaccine manufacturers also succeeded in obtaining the regulatory approvals for other IPVs in July 2012. However, this event raises a fundamental question about the Japanese vaccination policy as to whether the MHLW prioritizes health protection of the people over concerns regarding domestic vaccine manufacturers.

Before the 2013 partial amendment of Japan's Immunization Law, the only vaccines covered by the routine vaccination program were diphtheria, pertussis, polio, measles, rubella, Japanese encephalitis, tetanus, tuberculosis, and influenza only for the elderly. ${ }^{63,64}$ In addition to the above mentioned vaccines, the coverage now includes vaccines against Haemophilus influenza type b, child pneumococcus, HPV (since April 2013), varicella, and adult pneumococcus (since October 2014), and the MHLW plans to cover hepatitis B in 2016. However, the vaccines that protect against hepatitis A, rotavirus, mumps, and influenza are still not included in the routine vaccination program. Obtaining them puts a financial burden on the general public because they need to pay the extra expenses voluntarily by themselves without sufficient compensation for adverse events.

In the past, immunization problems repeatedly caused lawsuits against the government. The MMR vaccine was introduced in 1989 and was withdrawn in 1993 because of unintended side effects. ${ }^{29}$ As a result, the government faced a class-action lawsuit. The MHLW amended the Immunization Law in 1994 from being obligatory, to being the reasonable efforts of the people, with local governments' obligation to reduce the governments' liability. ${ }^{63}$ The measles monovalent vaccine and rubella monovalent vaccine were introduced in 1994, and the measles-rubella vaccine was introduced in 2006. Unfortunately, a new MMR vaccine or other 
combination vaccines are still not introduced. The unclear vaccination policy after 1993 decreased the vaccination rates among some generations. As a result, in 2000 to 2001, there were huge outbreaks of measles with approximately 200,000 to 300,000 cases. In 2008 , more than 11,000 cases were reported. In 2012-2013, there were at least 15,000 adult rubella cases mainly in metropolitan areas, and more than 40 cases of the congenital rubella syndrome were reported in 2014. ${ }^{65,67,68}$ The MHLW has started a vaccine promotion to eliminate rubella by 2020 when the Tokyo Olympic Games will be held. However, an effective provision of vaccination for adults remains as a challenging issue because susceptible adults voluntarily need to seek rubella vaccination at their own expense.

In the future, cervical cancer caused by HPV might follow a similar track as mumps and rubella outbreaks. An HPV vaccine was firstly approved in Japan with more than 2 years' vaccine lag in October 2009, and two HPV vaccines have been incorporated into the routine immunization schedule since April 2013. However, the MHLW has suspended the HPV vaccination promotion since June 2013, because of fears of adverse events, especially CRPS. ${ }^{30-32}$ Although the causality is debated, the HPV vaccination promotion is still on hold by the MHLW as of January 2015. The vaccine coverage among girls has reportedly decreased to nearly one tenth. This policy does not seem to be accepted among the global scientific community, with the exception of anti-vaccination groups. ${ }^{69,70}$ Thus, the Japanese vaccine policy still has many problems and controversies to be solved.

In the policy-making process, the bureaucrats of the MHLW have a strong power, and they control scholarly committee members who need research funds from the government. Such relationships are not limited to the vaccine field, but are widely prevalent throughout Japanese society. Nevertheless, the Japanese vaccination system needs more reforms so that the decision-making process can be independent, transparent, and scientifically based. For bureaucrats, the risk of developing vaccine-preventable diseases may not outweigh the trouble of health hazards related to vaccination. However, the Japanese should not overlook the benefit of preventing infectious diseases by using vaccines to promote public health. Medical professionals need to engage in educating the general public and the mass media more rigorously.

\section{Clinical study misconduct}

Currently, misconduct involving clinical study has become a major social problem in Japanese society. ${ }^{71-74}$ Japan had the third largest number of retracted papers due to fraud or suspected fraud in the world. This is the result of analyzing 2,047 retracted biomedical and life-science research articles as of May 2012. ${ }^{75}$ Surprisingly, it was revealed in June 2012, a Japanese anesthesiologist fabricated clinical studies for almost 2 decades, and accumulated at least 172 fabricated research papers. This could be the world record for papers fabricated by a single author. ${ }^{76}$

Under the Pharmaceutical Medical Devices Affairs Law, Good Clinical Practice (GCP) standard is a requirement with strict quality control of data for clinical trials to obtain market approval. However, GCP is not applied for postmarketing, investigator-initiated clinical studies not related to regulatory approval. It is up to the investigator's morals to ensure the quality and validity of the clinical studies in Japan. As mentioned before, pricing of drugs in a same class becomes almost similar under the universal health coverage. This imposes a difficult challenge for the pharmaceutical companies to differentiate their drugs and promote sales in the Japanese market. Under these circumstances, successive clinical study misconduct has emerged.

The antihypertensive drug valsartan (Diovan ${ }^{\circledR}$; Novartis, Basel, Switzerland) made by Novartis created one of the biggest scandals involving a pharmaceutical company in recent decades. $^{71-74,77}$ The drug was approved in the year 2000 for use in Japan and is sold globally. It belongs to the class of drugs known as angiotensin II receptor antagonist (ARB). Currently, seven ARBs are sold in Japan, and the market for ARBs is almost JPY 400 billion per year. Although the market is very competitive, the drug became the best-selling drug in 2012 with sales of JPY 100 billion. Since its approval, it has accumulated sales over JPY 1 trillion. After the approval of valsartan, post-marketing large-scale randomized clinical studies played an important role in the success of the drug. Those studies were performed as independent, investigatorinitiated clinical studies involving several famous universities with no stated conflict of interest. The researchers investigated the effectiveness of the drug to prevent cardiovascular events in addition to lowering blood pressure, and published the positive results in prestigious medical journals. ${ }^{78-80}$ The company boosted the sales by incorporating the so-called evidence-based clinical studies in the marketing materials with the recommendations of professors involved at the Japanese Society of Hypertension. However, statistical concerns were raised in 2012, ${ }^{81}$ and the trial data came under scrutiny. Third-party investigations revealed that a Novartis employee was responsible for analyzing data, and the company did in fact give research funding to the universities. 
Furthermore, when they compared the individual patients' raw data with the published data, they found that the analytics had been manipulated in a subgroup of patients to claim a higher effectiveness. This manipulation caused the retraction of several research papers, the resignation of professors, and the arrest of the statistician on suspicion of falsifying clinical data to overstate the drug's efficacy. ${ }^{77,82}$ However, the detailed truths concerning who had been responsible for the unprecedented scandal are still unknown as of January 2015. This misconduct led to unnecessary defrayment and increased cost of health insurance, but there is no clear punishment against such corrupted actions in the Japanese legal system. Nor was there a lawsuit to seek refunding from the pharmaceutical company, such as a qui tam lawsuit in the US..$^{83-85}$

Novartis Pharma has been involved in other scandals as well. In December 2014, the company failed to report more than 3,000 severe adverse drug reactions of 26 items to the authorities. ${ }^{77}$ In another clinical trial for a leukemia drug, employees of the company were secretly involved in devising the trial and received patients' data without informed consent. ${ }^{72,74}$ Such misconduct is not only limited to Novartis, but other pharmaceutical companies also have similar problems. ${ }^{74,86}$

In the cases described above, several challenges are worth noting. First, investigations by a university have limitations because they are conducted on a voluntary basis only within their own university. The review board cannot investigate other universities or pharmaceutical companies. Secondly, the investigations for alleged misconduct were sometimes very slow to be initiated, and the allegations were even ignored in some cases. Therefore, an independent third-party public organization like the Office of Research Integrity of the US may be required to investigate misconduct, and to respond with fairness to an allegation. The conventional closed scientific community is now being opened up by an inter-connected world: rigorous post-publication reviews by a wide variety of readers and whistle blowing through twitter and blogs have accelerated misconduct discussions. ${ }^{71}$ Another important point not to be overlooked is that the mass media sponsored by the pharmaceutical companies are often careful about disclosing alleged misconduct for fear of losing financial support. It should be cautiously questioned about the fairness and validity of drug advertisement in the media.

Traditionally, the Japanese medical community has largely relied on unrestricted funding from pharmaceutical companies. The total amount of the funding from 72 companies was JPY 483 billion and that from the government was only
257 billion in 2012. While the partnerships between industries and academia are necessary considering insufficient public budgets, the establishment of a more transparent system is essential to regain the public's trust. Japanese authorities are planning to introduce stricter regulation enforcement based on the criteria from the International Conference on Harmonization of GCP for a part of investigator-initiated clinical studies. They plan to implement several regulations on post-marketing clinical studies for advertisement, and the use of unapproved or off-label drugs. Some fear these regulations would increase the cost related to clinical studies, and decrease the activity of medical research and development. The concern would be a disadvantage that must be taken into account.

\section{Current challenges}

More than 50 years ago, the universal health care system was started to promote the health of the Japanese people. However, in regards to the clinical development of new and emerging pharmaceuticals, Japan has not been successful as symbolized by the drug lag problem, even though it is a country with high economic power, and a public in pursuit of good health. The Japanese pharmaceutical industry is in complete contrast to the Japanese automobile industry. The latter has a strong presence in the global market, while the former does not have much of a presence. The high nontariff entry barrier has protected the domestic pharmaceutical industry; as a result, they cannot develop international competitiveness. The trade deficit of pharmaceuticals has been increasing rapidly: JPY 1.62 trillion with JPY 1.94 trillion imports and JPY 320 billion exports in $2012 .{ }^{5}$

Table 2 summarizes current challenges, recently adopted strategies by the government, and unsolved problems. Under the impending threat from economic and demographic issues, the government faces new challenges regarding reforming the health care policy, including pushing the development of new pharmaceuticals and medical technologies. Japan's current prime minister is one of the very few top Japanese officials who understand the importance of health and medicine. Not only has he made the universal health coverage an integral part of Japan's foreign policy, as part of his domestic doctrine, he sees health care as one of the key strategies for increasing domestic economic growth. ${ }^{87,88}$ For example, the world's first clinical application using induced pluripotent stem (iPS) cells just started in 2014. ${ }^{89}$ The government plans to make a temporary conditional approval at the preliminary phase only for regenerative medicine to ensure earlier access of 
Table 2 Current challenges related to the benefit-risk assessment for pharmaceuticals in Japan

\begin{tabular}{|c|c|c|}
\hline Challenges & $\begin{array}{l}\text { Recently adopted strategies } \\
\text { by the government }\end{array}$ & Unsolved problems \\
\hline $\begin{array}{l}\text { Health hazards related } \\
\text { to pharmaceuticals } \\
\text { (“Yakugai” in Japanese) }\end{array}$ & $\begin{array}{l}\text { - Increasing staff for safety } \\
\text { monitoring at the PMDA } \\
\text { - Reinforcement of risk communication } \\
\text { and management }\end{array}$ & $\begin{array}{l}\text { - Possible increase of the health hazards } \\
\text { risk caused by the reduction of the drug lag } \\
\text { - Conservative risk assessment to avoid risks } \\
\text { as far as possible }\end{array}$ \\
\hline Drug lag & $\begin{array}{l}\text { - Increasing staff for regulatory } \\
\text { review at the PMDA } \\
\text { - Promotion of global clinical trials } \\
\text { - Decreasing regulatory review time } \\
\text { - Accelerated conditional approval } \\
\text { (only for regenerative medicine) } \\
\text { - Early access to unapproved drugs } \\
\text { (only in selected hospitals) } \\
\text { - Establishment of the Japan AMED }\end{array}$ & $\begin{array}{l}\text { - Propriety of a mandatory demand for } \\
\text { - Japanese patients data in clinical trials } \\
\text { - Delayed launch of domestic clinical trials } \\
\text { - Early access to novel pharmaceuticals especially } \\
\text { for patients with life-threatening diseases } \\
\text { - Limited competition through uniform drug pricing } \\
\text { under the universal health coverage } \\
\text { - Prohibition of a mixed medical treatment in the } \\
\text { public insurance }\end{array}$ \\
\hline Vaccination policy & $\begin{array}{l}\text { - Increased number of vaccine coverage } \\
\text { in the routine immunization program }\end{array}$ & $\begin{array}{l}\text { - Vaccine lag } \\
\text { - Effective provision of vaccination for } \\
\text { unimmunized persons } \\
\text { - More transparent, scientifically based } \\
\text { policy-making process }\end{array}$ \\
\hline $\begin{array}{l}\text { Clinical study } \\
\text { misconduct }\end{array}$ & $\begin{array}{l}\text { - Strict regulation implementation } \\
\text { for post-marketing clinical study including } \\
\text { long-term data preservation } \\
\text { - Increased transparency concerning } \\
\text { conflict of interest }\end{array}$ & $\begin{array}{l}\text { - Effective, prompt, and fair investigation against } \\
\text { misconduct allegations } \\
\text { - Financial recovery against unnecessary defrayment } \\
\text { - Overreliance on funding from pharmaceutical } \\
\text { companies } \\
\text { - Stagnation of study activities due to excessive } \\
\text { regulation }\end{array}$ \\
\hline
\end{tabular}

Abbreviations: PMDA, Pharmaceutical and Medical Devices Agency; AMED, Japan Agency for Medical Research and Development.

an emerging innovative treatment.In addition, as a partial exemption of the ban of a mixed medical treatment, the use of unapproved drugs will be admitted in selected hospitals if requested by patients. The Prime Minister's Cabinet has also developed a health and medical care strategy and passed a law establishing the Japan Agency for Medical Research and Development (AMED). This agency will aim to consolidate medical research funding, facilitate innovative research, and support the development of new pharmaceuticals and medical devices, with JPY 140 billion budget in FY 2015.

Considering the significant demographic change with an enormous fiscal burden, there will be no straightforward answer to solve every remaining problem simultaneously. Bringing more deregulation and competition in the pharmaceutical market may work, while a neoliberal policy, which might exacerbate inequality, will not be easily accepted in the Japanese egalitarian medical society. Stakeholders related to pharmaceuticals must keep in mind the fact that the most important goal is to provide the best available treatment to the patients.

\section{Conclusion}

The benefit-risk assessment in Japan has focused on averting the health hazards related to pharmaceuticals (Yakugai) rather than developing new treatments rigorously. Such a regulatory system has caused more than several years of the drug lag, while the solution is incompatible with the elimination of Yakugai because the lag potentially reduces the risk of unpredictable adverse events. The Japanese vaccination policy needs improvements so that the decision-making process can be more transparent and scientifically based, and the medical community must change the inappropriate relationship with the industry that gave rise to clinical study misconduct. Some of the problems surrounding pharmaceuticals are the result of centralized drug pricing control under the universal health coverage. Further reforms should be explored to facilitate innovative research and the development of novel therapeutics for patients who need them.

\section{Acknowledgments}

I thank Drs Masahiro Kami, Kenji Tsuda, Shunsuke Ono, Tetsutaro Matayoshi, and Mr Masahiro Takeda for their 
precious advice; Dr Mutsuko Ohnishi, Mr Larry Wesley Ward, Mr Ryuichiro Ohkawa, Mr Naoki Okada, and Ms Tomoyo Nishimura for their editorial assistance. My special thanks go to Navitas Clinic, Tokyo, Japan; Jyoban Hospital of Tokiwakai Group, Fukushima, Japan; Japanese Foundation for Cancer Research, Tokyo, Japan.

\section{Disclosure}

The author reports no conflict of interest in this work.

\section{References}

1. The Lancet Global Health Series [homepage on the Internet]. Japan: Universal Health Care at 50 years. Lancet. 2011 [updated August 30, 2011]. Available from: http://www.thelancet.com/series/japan. Accessed January 19, 2015.

2. Shibuya K, Hashimoto H, Ikegami N, et al. Future of Japan's system of good health at low cost with equity: beyond universal coverage. Lancet. 2011;378(9798):1265-1273.

3. Statistics Bureau, The Japan's Ministry of Internal affairs and Communications [homepage on the Internet]. The Statistical Handbook of Japan 2014; 2014 [updated September, 2014]. Available from: http://www. stat.go.jp/english/data/handbook/index.htm. Accessed January 19, 2015.

4. The Japan's Ministry of Health, Labour and Welfare [homepage on the Internet]. Estimates of National Medical Care Expenditure, FY 2012; 2014 [updated October 8, 2014]. Available from: http://www.mhlw.go.jp/ english/database/db-hss/enmce_2012.html. Accessed January 19, 2015.

5. The Japan's Ministry of Health, Labour and Welfare [homepage on the Internet]. Vision for the Pharmaceutical Industry 2013; 2013 [in Japanese, published June 26, 2013]. Available from: http://www. mhlw.go.jp/seisakunitsuite/bunya/kenkou_iryou/iryou/shinkou/dl/ vision_2013b.pdf. Accessed January 19, 2015.

6. The Japan's Ministry of Health, Labour and Welfare [homepage on the Internet]. Available from: http://www.mhlw.go.jp/english/. Accessed January 19, 2015.

7. The Japan's Pharmaceutical and Medical Devices Agency [homepage on the Internet]. Available from: http://www.pmda.go.jp/english/index. html. Accessed January 19, 2015.

8. Goldman M, Seigneuret N, Eichler HG. The innovative medicines initiative: an engine for regulatory science. Nat Rev Drug Discov. 2015; 14(1): $1-2$

9. Tominaga T, Asahina Y, Uyama Y, Kondo T. Regulatory science as a bridge between science and society. Clin Pharmacol Ther. 2011; 90(1):29-31.

10. The U.S. Food and Drug Administration [homepage on the Internet]. Available from: http://www.fda.gov. Accessed January 19, 2015.

11. The European Medicines Agency [homepage on the Internet]. Available from: http://www.ema.europa.eu/ema/. Accessed January 19, 2015.

12. The Japan's Pharmaceutical and Medical Devices Agency. Relief Service for Adverse Health Effects. Available from: http://www.pmda. go.jp/english/service/outline_r.html. Accessed January 19, 2015.

13. Tanimoto T, Tsubokura M, Mori J, Pietrek M, Ono S, Kami M. Differences in drug approval processes of 3 regulatory agencies: a case study of gemtuzumab ozogamicin. Invest New Drugs. 2013;31(2):473-478.

14. Tanimoto T, Kusumi E, Ono S. Review of novel therapeutics by three regulatory agencies. $N$ Engl J Med. 2012;367(12):1165-1166. [author reply 1166-1167].

15. Downing NS, Aminawung JA, Shah ND, Braunstein JB, Krumholz HM, Ross JS. Regulatory review of novel therapeutics-comparison of three regulatory agencies. N Engl J Med. 2012;366(24):2284-2293.

16. Hirai Y, Kinoshita H, Kusama M, Yasuda K, Sugiyama Y, Ono S. Delays in new drug applications in Japan and industrial R\&D strategies. Clin Pharmacol Ther. 2010;87(2):212-218.
17. Tsuji K, Tsutani K. Approval of new drugs 1999-2007: comparison of the US, the EU and Japan situations. J Clin Pharm Ther. 2010; 35(3):289-301.

18. Tanimoto T, Fukunaga S, Hori A, Yagasaki F, Ono S. Eltrombopag for chronic immune thrombocytopenia. Lancet. 2011;377(9781):1919. [author reply 1919-1920].

19. Asano K, Tanaka A, Sato T, Uyama Y. Regulatory challenges in the review of data from global clinical trials: the PMDA perspective. Clin Pharmacol Ther. 2013;94(2):195-198.

20. Makino S. [The current state of transfusion medicine in Japan]. Gan To Kagaku Ryoho. 2014;41(4):410-415. Japanese.

21. Yoshino I. [Treatment of cancer chemotherapy-associated anemia in Japan - conditions and issues]. Gan To Kagaku Ryoho. 2014;41(4): 426-431. Japanese.

22. The Pharmaceutical and Medical Device Regulatory Science Society of Japan. [Lessons from "Yakugai"]. 1st ed. Tokyo: Yakuji Nippo Ltd; 2012. Japanese.

23. Kajii T, Shinohara M. Thalidomide in Japan. Lancet. 1963;1(7279): 501-502.

24. Tateishi J. Subacute myelo-optico-neuropathy: clioquinol intoxication in humans and animals. Neuropathology. 2000;20(suppl):S20-S24.

25. Watts J. Tainted-blood revelation shocks Japanese. Lancet. 1998; 352(9127):554.

26. Saegusa A. Japanese officials were aware of HIV in blood products. Nat Med. 1998;4(9):991.

27. McCurry J. Japan compensates some of its hepatitis C victims. Lancet. 2008;371(9618):1061-1062.

28. Yasunaga $\mathrm{H}$. Risk of authoritarianism: fibrinogen-transmitted hepatitis $\mathrm{C}$ in Japan. Lancet. 2007;370(9604):2063-2067.

29. Ueda K, Miyazaki C, Hidaka Y, Okada K, Kusuhara K, Kadoya R. Aseptic meningitis caused by measles-mumps-rubella vaccine in Japan. Lancet. 1995;346(8976):701-702.

30. Gilmour S, Kanda M, Kusumi E, Tanimoto T, Kami M, Shibuya K. HPV vaccination programme in Japan. Lancet. 2013;382(9894):768.

31. Kinoshita T, Abe RT, Hineno A, Tsunekawa K, Nakane S, Ekeda S. Peripheral sympathetic nerve dysfunction in adolescent Japanese girls following immunization with the human papillomavirus vaccine. Intern Med. 2014;53(19):2185-2200.

32. Morimoto A, Ueda Y, Egawa-Takata T, et al. Effect on HPV vaccination in Japan resulting from news report of adverse events and suspension of governmental recommendation for HPV vaccination. Int J Clin Oncol. In press 2014.

33. Murashige N, Tanimoto T, Oshima Y. Interstitial lung disease and gefitinib. $N$ Engl J Med. 2010;363(16):1578-1579. [author reply 1579-1580].

34. Nishimura T, Tada H, Nakagawa M, Teramukai S, Matsui S, Fukushima M. Lessons from gefitinib-induced interstitial lung disease in Japan: problems in approval, pharmacovigilance, and regulatory decisionmaking procedures. Pharm Pract (Granada). 2006;4(4):168-178.

35. Avorn J. Powerful Medicines: The Benefits, Risks, and Costs of Prescription Drugs. Rev Upd ed. New York: Vintage; 2008.

36. Yamada T, Kusama M, Hirai Y, Arnold F, Sugiyama Y, Ono S. Analysis of pharmaceutical safety-related regulatory actions in Japan: do tradeoffs exist between safer drugs and launch delay? Ann Pharmacother. 2010;44(12):1976-1985.

37. Dmytrijuk A, Robie-Suh K, Cohen MH, Rieves D, Weiss K, Pazdur R. FDA report: eculizumab (Soliris) for the treatment of patients with paroxysmal nocturnal hemoglobinuria. Oncologist. 2008;13(9):993-1000.

38. Hillmen P, Hall C, Marsh JC, et al. Effect of eculizumab on hemolysis and transfusion requirements in patients with paroxysmal nocturnal hemoglobinuria. $N$ Engl J Med. 2006;355(12):1233-1243.

39. Hillmen P, Young NS, Schubert J, et al. The complement inhibitor eculizumab in paroxysmal nocturnal hemoglobinuria. $N$ Engl $J$ Med. 2004;350(6):552-559.

40. Takita M, Matsumura T, Kami M. Eculizumab in paroxysmal nocturnal hemoglobinuria. $N$ Engl J Med. 2006;355(26):2787. [author reply 2787-2788]. 
41. The Pharmaceutical and Medical Devices Agency. Soriris Review Report [homepage on the Internet]; 2010. Available from: http://www. pmda.go.jp/english/service/pdf/drugs/soliris_apr2010_e.pdf. Accessed January 19, 2015.

42. Shimazawa R, Kusumi I, Ikeda M. Delays in psychiatric drug development in Japan. J Clin Pharm Ther. 2012;37(3):348-351.

43. Shimazawa R, Ikeda M. Delays in neurological drug development in Japan. Intern Med. 2011;50(15):1565-1568.

44. Yonemori K, Hirakawa A, Ando M, et al. The notorious "drug lag" for oncology drugs in Japan. Invest New Drugs. 2011;29(4):706-712.

45. Tsuda K, Takahashi $Y$, Itokawa $T$, et al. Regulatory review of new drug applications for hematological malignancies in Japan. The 76th Annual Meeting of the Japanese Society of Hematology; October 31November 2, 2014; Osaka, Japan.

46. Hirai Y, Yamanaka Y, Kusama M, Ishibashi T, Sugiyama Y, Ono S. Analysis of the success rates of new drug development in Japan and the lag behind the US. Health Policy. 2012;104(3):241-246.

47. Ohwaki K, Nakabayashi T. Relationship between drug lag and factors associated with clinical trials in Japan. J Clin Pharm Tehr. 2014;39(6):649-652.

48. Honig PK. Recent trends and success factors in reducing the lag time to approval of new drugs in Japan. Clin Pharmacol Ther. 2014;95(5): 467-469.

49. Hojo Y. [homepage on the Internet]. Toward the Globalized PMDA; 2014 [in Japanese, published April 24, 2014]. Available from: http:// www.pmda.go.jp/regulatory/file/presentation/executives/EX-B100Hojo.pdf. Accessed January 19, 2015.

50. Ishibashi T, Kusama M, Sugiyama Y, Ono S. Analysis of regulatory review times of new drugs in Japan: association with characteristics of new drug applications, regulatory agency, and pharmaceutical companies. J Clin Pharm Ther. 2012;37(6):657-663.

51. Maeda H, Kurokawa T. Regulatory review time for approval of oncology drugs in Japan between 2001 and 2014. Considerations of changes, factors that affect review time, and difference with the United States. J Clin Pharmacol. In press 2015.

52. Nobuyama M, Kusama M, Ono S. The relationship between the clinical development pathway and drug lag. The 36th Annual Meeting of the Japanese Society of Clinical Pharmacology and Therapeutics; December 9-11, 2014; Tokyo, Japan [in Japanese]. Available from: http:// www.f.u-tokyo.ac.jp/ regsci/files/14JSCPT_nobuyama.pdf. Accessed January 19, 2015.

53. Kami M. [The Medical Swindle]. 1st ed. Tokyo: Kodansha; 2014. Japanese.

54. Hashimoto H, Ikegami N, Shibuya K, et al. Cost containment and quality of care in Japan: is there a trade-off? Lancet. 2011;378 (9797):1174-1182.

55. The Japan Pharmaceutical Manufactures Association [homepage on the Internet]. Drug Pricing System in Japan; 2012 [published June 6, 2012]. Available from: http://www.jpma.or.jp/english/parj/pdf/2013_appendix. pdf. Accessed January 19, 2015.

56. Kanovos P, Ferrario A, Vandoros S, Anderson GF. Higher US branded drug prices and spending compared to other countries may stem partly from quick uptake of new drugs. Health Aff (Millwood). 2013; 32(4):753-761.

57. The Japan's Ministry of Health, Labour and Welfare [homepage on the Internet]. Comparison of New Drug Pricing between Japan and the EU; 2013 [in Japanese, published February 27, 2013]. Available from: http://www.mhlw.go.jp/stf/shingi/2r9852000002w6r3att/2r9852000002w6uj.pdf. Accessed January 19, 2015.

58. Experts in Chronic Myeloid Leukemia. The price of drugs for chronic myeloid leukemia (CML) is a reflection of the unsustainable prices of cancer drugs: from the perspective of a large group of CML experts. Blood. 2013;121(22):4439-4442.

59. The Japan's Ministry of Health, Labour and Welfare [homepage on the Internet]. The Estimation of Switching Rates to Generic Drugs; 2013 [in Japanese, published February 27, 2013]. Available from: http://www. mhlw.go.jp/stf/shingi/2r9852000002w6r3-att/2r9852000002w6us.pdf. Accessed January 19, 2015.
60. Tanimoto T, Murashige N, Hosoda M, et al. Vaccination for whom? Time to reinvigorate Japanese vaccine policy. Lancet. 2012;380(9854): 1647.

61. Hosoda M, Inoue H, Miyazawa Y, Kusumi E, Shibuya K. Vaccine-associated paralytic poliomyelitis in Japan. Lancet. 2012;379 (9815):520.

62. Tanimoto T, Kusumi E, Hosoda K, Kouno K, Hamaki T, Kami M. Concerns about unapproved meningococcal vaccination for eculizumab therapy in Japan. Orphanet J Rare Dis. 2014;9:48.

63. Murashige N, Matsumura T, Masahiro K. Disseminating Japan's immunisation policy to the world. Lancet. 2011;377(9762):299.

64. Murashige N. Japan's immunisation policy in routine, pandemic and post-tsunami situations. Int J Clin Pract. 2011;65(11):1126-1131.

65. Saitoh A, Okabe N. Recent progress and concerns regarding the Japanese immunization program: addressing the "vaccine gap". Vaccine. 2014;32(34):4253-4258.

66. Shimazawa R, Ikeda M. The Vaccine gap between Japan and the UK. Health Policy. 2012;107(2-3):312-317.

67. Ujiie M, Nabae K, Shobayashi T. Rubella outbreak in Japan. Lancet. 2014;383(9927):1460-1461.

68. Lambert N, Strebel P, Orenstein W, Icenogle J, Poland GA. Rubella. Lancet. In press 2015.

69. Larson HJ, Wilson R, Hanley S, Parys A, Paterson P. Tracking the global spread of vaccine sentiments: the global response to Japan's suspension of its HPV vaccine recommendation. Hum Vaccin Immunother. 2014;10(9):2543-2550.

70. The World Health Organization [homepage on the Internet]. Global Advisory Committee on Vaccine Safety Statement on the Continued Safety of HPV Vaccination; 2014 [published March 12, 2014]. Available from: http://www.who.int/vaccine_safety/committee/topics/hpv/GACVS_ Statement_HPV_12_Mar_2014.pdf?ua=1. Accessed January 19, 2015.

71. Tanimoto T, Kami M, Shibuya K. Research misconduct and scientific integrity: a call for a global forum. Lancet. 2013;382(9896):940.

72. Tanimoto T, Kami M, Shibuya K. Misconduct: Japan to learn from biomedical cases. Nature. 2014;512(7515):371.

73. Normile D. Tampered data cast shadow on drug trial. Science. 2013;341(6143):223.

74. Normile D. Faulty drug trials tarnish Japan's clinical research. Science. 2014;345(6192):17.

75. Fang FC, Steen RG, Casadevall A. Misconduct accounts for the majority of retracted scientific publications. Proc Natl Acad Sci US A. 2012;109(42):17028-17033.

76. Cyranoski D. [homepage on the Internet]. Retraction record rocks community. Nature. 2012. Available from: http:/www.nature.com/news/ retraction-record-rocks-community-1.11434. Accessed January 19, 2015.

77. McCurry J. Former Novartis employee arrested over valsartan data. Lancet. 2014;383(9935):2111.

78. Lancet Editors. Retraction-valsartan in a Japanese population with hypertension and other cardiovascular disease (Jikei Heart Study): a randomised, open-label, blinded endpoint morbidity-mortality study. Lancet. 2013;382(9895):843.

79. Anon. Retraction of: effects of valsartan on morbidity and mortality in uncontrolled hypertensive patients with high cardiovascular risks KYOTO HEART Study [Eur Heart J. 2009;30:2461-2469]. Eur Heart J. 2013;34(14)

80. Japanese Society of Hypertension. Japanese Society of Hypertension official comment on valsartan papers. Hypertens Res. 2013;36(11): 923.

81. Yui Y. Concerns about the Jikei Heart Study. Lancet. 2012;379 (9824):e48.

82. Yui Y. Prevention of misconduct in clinical trials in Japan. Lancet. 2014;384(9948):1098

83. Kesselheim AS, Studdert DM. Whistleblower-initiated enforcement actions against health care fraud and abuse in the United States, 1996 to 2005. Ann Intern Med. 2008;149(5):342-349.

84. Outterson K. Punishing health care fraud-is the GSK settlement sufficient? N Engl J Med. 2012;367(12):1082-1085. 
85. Kesselheim AS, Studdert DM, Mello MM. Whistle-blowers' experiences in fraud litigation against pharmaceutical companies. $N$ Engl $J$ Med. 2010;362(19):1832-1839.

86. Inagaki K. Takeda pharmaceutical admits to improper drug ads. Wall Street J. 2014. Available from: http://www.wsj.com/articles/SB1000 1424052702304360704579416861673857036 . Accessed January 19, 2015.

87. The Prime Minister of Japan and His Cabinet [homepage on the Internet]. Abenomics: We are Accelerating the Implementation of Our Committed Reforms; 2014 [updated November 4, 2014]. Available from: http://www.kantei.go.jp/jp/singi/keizaisaisei/pdf/kaikakudankouEN. pdf. Accessed January 19, 2015.
88. Cyranoski D. Japan aims high for growth. Nature. 2013;497(7451): 548.

89. Cyranoski D. Japan stem-cell trial stirs envy. Nature. 2014;513(7518): 287-288.

\section{Publish your work in this journal}

Drug Design, Development and Therapy is an international, peerreviewed open-access journal that spans the spectrum of drug design and development through to clinical applications. Clinical outcomes, patient safety, and programs for the development and effective, safe, and sustained use of medicines are a feature of the journal, which has also been accepted for indexing on PubMed Central. The manuscript management system is completely online and includes a very quick and fair peer-review system, which is all easy to use. Visit http://www.dovepress.com/testimonials.php to read real quotes from published authors.

Submit your manuscript here: http://www.dovepress.com/drug-design-development-and-therapy-journal 